\title{
Problem Solving as a Pedagogical Practice: Useful Conceptions of Professional Learning
}

\author{
Michelle Lang \\ Sir Adam Beck Primary School Canada
}

\author{
Immaculate K. Namukasa \\ The University of Western Ontario, Canada
}

\begin{abstract}
Problem solving as a pedagogical practice is a recent focus of mathematics education research and of professional learning. This study employs the phenomenographic framework for studying teachers' conceptions of ongoing professional learning opportunities focused on the teaching of mathematics through problem solving. Eleven grade 7 to 8 school teachers who participated in ongoing professional learning over the course of one to five years were purposively selected. Survey method was employed. Findings from the study reveal that most teachers view professional learning mainly as a source for ideas and resources, whereas others hold more complex views ranging from viewing professional learning as an opportunity for sharing strategies with colleagues, to seeing professional learning as an opportunity for deepening understandings of learning, and as a catalyst for change in practices of teaching mathematics. The study recommends teacher professional development programs to focus on developing more sophisticated conceptions of professional learning among teachers.
\end{abstract}

\section{Introduction}

Problem solving as a learning approach has a long history in many countries [1] including Canada. It is problem solving as a pedagogical practice that is a more recent focus of research and professional learning. In Ontario, several school boards have recently focused on teaching through problem solving. Teaching through problem solving is identified as a practice that encompasses the majority aspects of mathematics reform teaching practices. Schoenfeld maintains that problem solving research has to move to theoretical explorations that are broader than, say, studying methods used by expert problem solvers [1]. This article reports on teachers' varying conceptions of ongoing professional learning focused on the teaching of mathematics through problem solving.

The phenomenography theoretical framework motivates this focus on varying conceptions of professional learning, particularly the categorization and expansion of these conceptions. A group of
Grade 7 and 8 teachers who engaged in professional learning over the course of one to five years completed two surveys. Teacher's conceptions of professional learning and how these might contribute to classroom practice were investigated. We asked: How did teachers experience, or conceive, ongoing, professional learning opportunities focused on the teaching of mathematics through problem solving? To investigate this question we collected data on two questions: What is the diversity of categorization of mathematics teachers' conceptions of their ongoing professional learning? In what ways do teachers' conceptions of their ongoing professional learning suggest how their experiences might be enacted in the classroom? The overall objective of the study was to explore conceptions of professional learning that might be more productive for teaching.

\section{Professional Learning in Ontario}

This study involved 11 teachers from a School Board in Ontario, Canada who participated in ongoing, professional learning over the course of one to five years. These teachers were part of 28 Intermediate (specifically, grades 7 to 8) Lead Math Teachers (ILMTs) identified by the board in the fall of 2004 and participated in a half-day professional learning sessions over the course of the 2004-2005 school year. Many of these teachers then continued in the intermediate lead math teacher role in subsequent years, while others were replaced due to changes at the school level. Data was collected in 2008-2009.

The ILMTs engaged in a variety of professional learning models, including: planning lessons together - collaborative planning; observing and reflecting on lessons together - lesson study; and reciprocal peer coaching. The overarching goal in all sessions was to shift teacher practice to reflect reformoriented approaches - specifically a teaching mathematics through problem solving approach. All professional learning sessions, except for the lesson study cycles and reciprocal peer coaching that occurred in classrooms, were facilitated by the first author, Lang. The sessions took place centrally within the Board's Education Centre, and were two and one-half hours in length. Nine or eight sessions 
took place every school year, one every month of the school year.

During the first, second and third year of the ongoing professional learning, ILMTs sessions focused on teaching resources developed both by the provincial ministry of education and some of those developed by commercial publishers to support teaching through problem solving. In the first and second year, ILMT's also engaged in lesson studies on selected units. In the third year ILMTs jointly developed several grades 7 and 8 units. During the fourth year ILMTs reflected on a framework of teaching mathematics that focused on building Math learning communities in schools.

\section{Teaching Mathematics through Problem Solving}

Over the past three decades, there has been a significant shift from a traditional focus, in both research literature and curriculum policy, in the way in which doing mathematics, teaching and learning of mathematics are understood. To offer working definitions, we mention only selected examples here: Schoenfeld argues, "A major purpose of mathematics instruction is to help students learn to think mathematically" [3] (p. 164). He goes on to state that "thinking mathematically consists not only of mastering various facts and procedures, but also in understanding connections among them ... [as well as] being able to apply one's formal mathematical knowledge flexibly and meaningfully" (p. 164). The set of activities that students engage in when doing and learning mathematics as highlighted by reform educators is more closely aligned to mathematicians practice than to activities of a majority traditional school mathematics lessons. Fosnot and Dolk, building on van Hans Freudenthal's understanding of mathematics "not as a closed system, but rather as an activity ... of mathematizing reality" [4] (p. 7) describe learning mathematics as "interpreting, organizing, inquiring about, and constructing meaning through a mathematical lens” (p. 18). Sfard, too, sees the shift as one reflecting a change in our understanding of learning mathematics: learning "arises mainly from one's attempt to make sense of other people's visions of this world" [5] (p. 166). It is "a form of discourse ... [in which] individual learning originates in communication with others" (p. 166) [5].

There are varied approaches to and "multiple interpretations of what mathematical problem solving is” (p. 524) [2]. For the purposes of the study reported here, "teaching through problem solving" was defined as an approach to the teaching of mathematics wherein the teacher: (a) poses an appropriately challenging mathematical problem (task, question, exercise, or activity) to the class, (b) students work individually or collaboratively to solve the problem using tools and strategies that make sense to them, and (c) the teacher then facilitates the sharing and justification of students' strategies and solutions in order to make connections among and highlight the important mathematical concepts in the problem.

Considering teaching through problem solving as an umbrella term for teaching mathematics in reform ways, this kind of teaching goes hand in hand with shifts in conceptions of mathematics, its teaching and learning [6]. Hiebert and Wearne identify three signposts of teaching through problem solving: "allowing students to struggle with challenging problems, examining increasingly better solution methods, and providing appropriate information at the right times" [7] (p. 5). Stein, Boaler and Silver note specific actions for a teacher during problem solving lessons: "the scaffolding of students' thinking, a sustained press for students' explanations, thoughtful probing of students' strategies and solutions, [and] helping students accept responsibility for, and gain facility with, learning in a more open way" [8] (p. 253).

Living up to this new vision of teaching is no easy task for teachers of elementary and lower secondary classes who are usually not mathematics specialists and most of whom have more experience with traditional mathematics learning approaches. In fact, learning to adopt newer roles for teachers requires, among other characteristics, "conceptual sophistication" [9] (p. 293). More than simply encouraging students to solve and justify solutions to problems, teachers need, among many other requirements, to be able to "build on students' existing mathematical knowledge (both formal and informal)" [10] (p. 274), and to "interpret idiosyncratic student responses, prompt multiple interpretations, [and] trace misinterpretations" [11] (p. 293). To support teachers in meeting this challenge, effective mathematics pre-service and inservice programs are needed.

Research on teaching of mathematics through problem solving in the context of in-service professional development and pre-service teacher education is growing. Courses, especially when they actively engage teachers in the solving of mathematical problems themselves, help teachers to (a) experience mathematics learning that is not limited to mastering facts and procedures, (b) consider the benefits of teaching mathematics in nontraditional ways, and (c) reflect on and reconsider their conceptions, beliefs and attitudes toward mathematics [11]. However, as Gadanidis and Namukasa state, "a single course experience cannot create comprehensive or permanent change in teachers' perceptions of mathematics and mathematics teaching” [11] (p. 21). Also, needed are models of ongoing professional development in mathematics that continue to broaden teachers' 
mathematical understanding, and beliefs about mathematics and about its teaching and learning.

\section{Professional Learning Conceptions}

Much research has been conducted over the past two decades into what makes professional development in mathematics effective (e.g., Guskey, [12]. Since "professional development programs are systematic efforts to bring about change in the classroom practices of teachers” [12] (p. 381), the effectiveness of a particular professional development (PD) program is tied to its ability to effect teacher change. Moreover, contributing to professional development outcomes are several other factors including individual teacher characteristics such as conceptions and efficacy for teaching plus socio-institutional factors.

Teachers' conceptions about teaching, in general, may significantly influence their instructional practice [13, 14, 15]. Akerlind's study identified a spectrum of teaching orientations at higher education institution ranging from orientations centered on facilitating learning to those centered on delivering the knowledge of the discipline to students [13].

Wood investigated variation in the ways in which teacher candidates understand teaching. Two of the conceptions experienced by the student teachers focused on the teacher or the act of teaching, while the third, and "most powerful understanding of teaching ... is seen as preparing school students to be reflective" [15] (p. 89). Not only is a student-centered conception of teaching more sophisticated, it is also more likely to produce high quality learning outcomes amongst students [13].

A range of course activities including activities that cause disequilibrium or doubt in teachers' conceptions and those that offer opportunities for reflection have been observed to evoke changes in teachers' conception. Phenomenographers, however, argue that professional development ought to encourage teachers to develop broader conceptions about teaching [14, 16, 17].

Phenomenography aims to "find out the different ways in which people experience, interpret, ... perceive, or conceptualize various aspects of reality" [18] ( p. 178). Although similar to phenomenology in its focus on understanding phenomena, phenomenography takes a different perspective. According to Marton, phenomenography uses a second-order perspective which seeks to "make statements about people's ideas about the world (or about their experience of it)" [18] (p. 178) rather than seeking to make statements about the world itself. In other words, phenomenographic investigations are "not directed at the phenomenon as such, but at the variation in people's ways of understanding the phenomenon" [19] (p. 56).

From a phenomenographic perspective, "different conceptions are seen as logically related in a nested hierarchy of inclusiveness" [14] (p. 636). Therefore, when speaking about helping teachers to develop broader conceptions, it is a "conceptual expansion approach [rather than] a conceptual change approach" [14] (p. 636) that is suggested. Indeed, "less sophisticated conceptions are regarded not so much as wrong, but as incomplete, lacking awareness of key aspects of the phenomenon" [14] (p. 637). According to Marton and Tsui, the best way to extend how an individual understands a phenomenon is to help that individual to discern the critical features of a phenomenon by varying the different aspects or features of that phenomenon [17]. Marton and Tsui describe patterns of variation - contrast, generalization, separation, and fusion that can be used as strategies for extending an individual's conception of a phenomenon. Certain researchers are using patterns of variation in the design of mathematics learning tasks [17].

Akerlind applies patterns of variation to facilitate conceptual expansion of his teacher candidates' understandings of teaching [14]. He defines the following key activities: First, engaging teachers in comparing parts (such as a particular teaching situation, students' learning goals, and a teacher's expectation for students' actions) with wholes (such as a teacher's goals and teaching actions). This comparison of parts and wholes enables relating the phenomenon of teaching and to that of learning. Second, activities which engage teachers in making generalizations after studying different wholes (such as comparing two different ways of seeing a particular teaching situation or ways of understanding student learning). Third, activities that involve separating parts by studying variations that might result even within the same whole (such as when two students respond to the same mathematics task or lesson differently). And fourth, activities centered on discerning the parts of a whole so as to fuse the part-whole structure of a teaching-learning phenomenon together. This fusing may be done by studying components of teacher's professional learning or teaching experiences.

To summarize, teachers' conceptions of professional learning in mathematics can be expanded through an ongoing process that explicitly addresses four key strategies: (1) contrasting teachers' goals and actions in teaching with goals and expectations for student actions; (2) generalizing to see that there are various ways of understanding student learning; (3) separating the different ways that students respond to the same task; and (4) fusing the disparate components of professional learning opportunities into a holistic learning outcome. 


\section{Research Approach}

For research design, according to Svensson, the "most central characteristics [of phenomenography] are the explorative character of the data collection and the contextual analytic character of the treatment of data" [20] (p. 169). As Larsson and Holmstrom state, "we can get information about peoples' conceptions of a given phenomenon through their speech and actions” [19] (p. 56). For this reason, open-ended interviews are the preferred phenomenographic method of data collection [19, 20]. In a phenomenographic study, the ways in which a phenomenon is experienced or conceptualized is not predefined, but instead emerges from the data [13]. Data analysis, then, begins with "a search for meaning, or variation in meaning [the categories of description], across interview transcripts, and is then supplemented by a search for structural relationships between meanings [the outcome space]" [13] (p. 324). According to Akerlind, "the whole process [must be] a strongly iterative and comparative one, involving the continual sorting and resorting of data” [13] (p. 324).

The outcome of a phenomenographic study is to ascertain a set of categories of description - "the complex of possible ways of viewing [italics added] various aspects of [a phenomenon]" [18] (p. 197). The basic unit of description in phenomenographic research is a conception [16], although — as Marton and Pong note — various other terms such as 'ways of conceptualizing', 'ways of experiencing', 'ways of seeing'... [and] 'ways of understanding' [16] (p. 336) have been used. Conceptions, then, are represented in the form of categories of description. However, these categories of description are "not just a set of different meanings, but a logically inclusive structure relating the different meanings" [13] (p. 323). The categories of description developed by the researcher to represent different ways of experiencing a phenomenon are "further analyzed with regard to their logical relations in forming an outcome space [italics added]" [16] (p. 335) for the study. A few researchers have for instance studied outcome spaces for teachers' perceptions of their professional development experiences. The present study explores teachers' varying conceptions of ongoing professional learning.

\section{Research Setting}

Eleven respondents who participated in at least the last year of the ongoing, collaborative professional learning in mathematics were purposively solicited from a total of 28 ILMTs. Four ILMTs fully completed both the online and onsite survey, six ILMTs completed only the onsite professional learning survey, and one ILMT completed only the background part of the online survey. We analyzed only data from the ten ILMTs who fully completed the questionnaires. Both the online and the onsite surveys were anonymous and independent of each other.

The online survey contained 8 questions about the background of teachers, 3 questions on perceived effect of professional learning on teachers as learners, teachers and leaders, and 8 questions on understandings of confidence in ability to teach through problem solving. Sample questions included: What effect have the professional learning opportunities in mathematics over the past five years had on your: (a) Development as a learner? (b) Teaching of mathematics?

Response to the online survey was limited. Four teachers answered the background questions and 11 of the 19 questions, and only two teachers completed all 19 questions. To enable more meaningful analysis of teachers' experiences of professional learning, a request to use data collected from an onsite professional learning survey that had been administered primarily to solicit feedback on the professional learning from the learning series that occurred during that, 2008-2009, school year was submitted and approved by the University and the School Board Sub-Research Ethics committee. As a source of secondary data, the onsite survey contained three questions addressing professional learning in mathematics:

1. In what mathematics professional learning opportunities have you participated over the last three years?

2. Which opportunities do you feel most contributed to your professional growth as a teacher of mathematics? Please elaborate.

3. What opportunities would you like to see available to you in the 2009-2010 school year? Please be specific and include any new ideas.

The onsite professional learning survey responses tended to be much shorter in length - one or two phrases per question. Based on the similarities in the professional learning opportunities listed for the background question in each of the two surveys, we speculated that four of the five teachers who anonymously responded to the online questionnaire were part of the ten who completed the anonymous onsite professional learning survey. Thus, anonymity and confidentiality were maintained because although it was possible to identify membership in the ILMT group from the survey responses, it was not possible to identify specific individuals.

\section{Data Analysis}

In order to describe the various ways that different teachers experienced a phenomenon the 
first stage in the data analysis involved identifying phrases from the online survey data that described ILMTs' professional learning experiences. Five categories of description emerged during the first sort. We "sought to formulate [and justify] progressively more complete and refined descriptions of the [various] conceptions" [13] (p. 325). Examining the onsite survey responses during the second stage of the data analysis yielded more ways in which teachers experienced professional learning in mathematics. As a result, there was a broadening of categories from five to seven to encompass all of the varying experiences evident in the complete online and onsite survey data set. Recognizing that, in phenomenographic analysis, it is important to "maintain an open mind ... minimizing any predetermined views or too rapid foreclosure in views about the nature of the categories of description" [13] (p. 323), during the third stage of the data analysis notes were made about the categories that had emerged and then all of the phrases re-sorted according to new criteria. The fourth stage involved trying out another set of emergent criteria that had more categories, however, these categories did not meet the "three primary criteria for judging the quality of a phenomenographic outcome space” [13] (p. 323): (a) each category reveals something distinctive, (b) categories are logically related, and (c) there are as few categories as possible. The fifth stage involved revisiting the seven categories from the earlier sort with the intent to look closely at the participants responses to examine what was being said and how it was being said in order to allow categories of description to emerge which most accurately reflected the professional learning experiences of the teachers. As a result, four of the seven categories were combined into one category. To the extent that further analysis of the phrases yielded no further change in the categories themselves or the distribution of phrases among the categories the four conceptions that had emerged, we felt that these were a "reasonably stable set of categories" [13] (p. 325). The sixth step in the analysis, then, was to "investigate the internal relations between the categories" [19] (p. 58) in order to construct the outcome space. This final step involved returning to individual teachers' whole sets of responses to identify the conceptions evident in each teacher's complete set of responses. It appeared that some teachers demonstrated only one or two of the four conceptions, while others demonstrated all four conceptions. The distribution of conceptions across the whole group was analyzed to establish whether that an inclusive hierarchy existed among the categories of description.

\section{Findings}

\subsection{Ways of Experiencing Professional Learning in Mathematics}

During the analysis of the survey data, four ways of experiencing mathematics professional learning opportunities emerged. The four categories of description are: (a) seeing the mathematics professional learning as a source for new ideas, strategies, and resources, the gatherer; (b) seeing the mathematics professional learning as an opportunity to share and discuss with colleagues new ideas and strategies, the networker; (c) viewing mathematics professional learning as an opportunity to deepen understanding of mathematics teaching and learning, the internalizer; and (d) viewing the mathematics professional learning as a catalyst for change in practice, the enacter. Table 1 displays the distribution of conceptions of professional learning by ILMTs.

8.1.1. Category A: the gatherer. The focus of this category is on collecting resources, whether they are material resources such as student activity pages or lesson plans. The goal of attending mathematics professional learning for the teacher that we have labeled the gatherer is to acquire new resources. Teachers who valued reviewing a prepared mathematics lesson, trying out the student tasks, and going away with a package that includes both the lesson plan and student handouts exemplify the experience described in this category.

Two responses to a question on the opportunities that most contributed to the ILMT's professional growth illustrate this way of understanding professional learning:

Great ideas on how to deliver a unit with concrete ideas. Also, good explanation as to why to include certain activities (ILMT 6); [Sessions] were very practical. I came away with strategies, ideas, etc. (ILMT 7); sharing of lessons, exemplars [and] integration of technology [most contributed to my professional growth] (ILMT 9).

In summary, for teachers with this view, the focus is on gaining new tools, methods or strategies for the teaching and learning. These teachers look forward to receiving practical resources when they attend mathematics professional learning sessions. As shown in Table 1, all ten of the ILMTs in the present study demonstrated this conception of professional learning in mathematics. 
8.1.2. Category B: The Networker. In this category, experience of professional learning in mathematics extends from the focus on gathering resources described in Category A to a focus on collaborating and sharing those resources with other teachers as well participating in a learning community.

As evident in the following quotes, the purpose of mathematics professional learning opportunities, for the networker, is to exchange ideas and resources: "I really like to be able to share ideas with colleagues and get new ideas .... to go to sessions to learn new ways of teaching and sharing with other teachers” (ILMT 2); “[professional learning opportunities which contributed to my professional growth were] a chance for dialogue with other math teachers about what they are doing in their classrooms" (ILMT 8).

The focus on sharing with colleagues in Category B does not appear to exclude Category A's focus on obtaining resources. In fact, the acquisition of new resources and ideas is also seen as part of teachers' experience in Category $\mathrm{B}$, thus suggesting an expanded conception of professional learning in mathematics. The way in which these two foci become integrated in Category B is illustrated in the following phrases: The opportunities which most contributed to my professional growth were the "sharing [illustrating the experience represented by Category B] of lessons, exemplars [illustrating the experience represented by Category A] [and the] integration of technology” (ILMT 9).

Although eight of the ten teachers whose data was analyzed showed evidence of viewing professional learning in mathematics as both a source for new ideas, strategies, and resources (Category A) and an opportunity to develop and share ideas and resources with their colleagues (Category B), as shown in Table 1, at least one teacher, ILMT 6, as evinced in his/her responses to all three questions on the onsite survey, demonstrated only Category A.

8.1.3. Category C. The Internalizer. For the internalizer, the goal of participating in professional learning in mathematics is to deepen one's own understanding of mathematics and one's knowledge about the teaching and learning of mathematics. Teachers with this conception seem to see professional learning as an opportunity to reflect on their teaching practices and challenge what they know and how they teach. Acknowledging learning and growth, both their own and their students', is a characteristic aspect of teachers who experience professional learning in mathematics in this way. For instance, IMLT 2 wrote:

I have learned so much about teaching math over the past five years. My own personal understanding of mathematics has dramatically increased as well .... Student understanding of concepts [has] increased, I believe, as a direct result of my professional learning.

Whereas IMLT 3 responded this way:

[Professional learning opportunities in mathematics] taught me to find more than one way to solve a problem - numerous open ended problems that I have solved provided me with the experience I need to be able to understand how students learn and how to guide them if they are having difficulty - learned what is was like to struggle with a problem and then what it felt like when I finally figured it out .... I I had a better understanding of how the process of teaching through problem solving looked and felt from all of my PD - developed a better understanding of how students learn through all of my PD.

Category $\mathrm{C}$ also represents an increase in complexity of how professional learning in mathematics is experienced, in the sense that the experience of professional learning in mathematics represented by this category also includes the experience of gathering resources (Category A) and networking with other teachers (Category B). This inclusive, or expanding, experience is illustrated in a phrase from ILMT 7:

[In the 2009-2010 school year, I would like the opportunity for] more in-school time to collaboratively plan [illustrating Category B] units in math; more in-service days which give us great ideas [illustrating Category A] . . . [and] help for moving IEP'd, Level 1-2 kids beyond in math [illustrating Category C].

In summary, for teachers with this view of mathematics professional learning, growth in their own understanding of the teaching and learning of mathematics is also central to their professional learning experiences. In mathematics professional learning sessions, these teachers may seek opportunities to challenge their current ways of thinking about the teaching and learning of mathematics and to develop new understandings. The experience represented by Category $\mathrm{C}$ is more complex than for previous categories because it includes awareness of an increasing number of aspects of professional learning in mathematics: the opportunity for gathering new ideas and resources, developing and sharing ideas and strategies with colleagues, and focusing on students' learning.

8.1.4. Category A: The Enacter. For the ILMT, who we have referred to as an enacter, professional learning opportunities in mathematics are seen as sources of catalysts for change in classroom practice. Reflecting on tasks or lessons implemented in the classroom, discussing students' strategies and 
solutions to problems, and identifying ways in which teaching practice has grown characterize the experience described in this category.

The following phrases illustrate the way of understanding professional learning in mathematics represented by Category D.

[Professional learning opportunities in mathematics have] helped me think about how to apply primary stuff learned to intermediate teaching, not just get stuck teaching from the textbook, trying to make sure [I include] enough group work and higher order questions. . . . helped me think about and change practices to use more manipulatives, group work, problem solving methods. I spend more time making sure students understand concepts, can describe them, and apply them. (ILMT 1)

The increasing complexity of how professional learning in mathematics is experienced that we saw in the first three categories continues with this fourth and final category. Teachers who have this conception not only experience professional learning in mathematics as a catalyst for change, but they also experience it as an opportunity to deepen their own understanding of the teaching and learning of mathematics (Category C), as a support network (Category B), and as a source for resources (Category A). This greater complexity and inclusivity is illustrated in the phrases from by ILMT 3:

I know that [the ongoing, collaborative professional learning in mathematics] played a huge role in my development introduced me to great resources, like Van de Walle and Dr. Small [illustrating Category A], which have also influenced my teaching practice - provided me with opportunities to learn by doing, discuss my learning with colleagues, share ideas and teaching strategies [illustrating Category B] - great math learning community where I could question how I teach and think [illustrating Category C] and feel safe encouraged me to think outside the box which I now encourage my students to do [illustrating Category D]. (ILMT 3, online survey, Question 18)

In summary, teachers who conceive of mathematics professional learning in this way strive to enact what they have learned about improving the teaching and learning of mathematics in their classrooms. They are willing to take risks and change their practices to improve student learning. This complex and inclusive view of professional learning in mathematics includes an emphasis on practicing new ways of teaching, in addition to deepening understanding and sharing ideas and resources with other teachers.
Thus, teachers in the study experienced professional learning opportunities in mathematics in different ways. Some teachers seemed to see professional learning mainly as a source for material resources, while others seemed to hold more complex views that include opportunities for collaboratively developing knowledge about the teaching and learning of mathematics and integrating new learning in the classroom.

In general, teachers who viewed professional learning in mathematics as a catalyst for change (Category D) also see professional learning as opportunities for gathering new ideas and resources (Category A), networking and sharing with colleagues (Category B), and deepening their own understanding about the teaching and learning of mathematics (Category C). Similarly, one teacher whose responses revealed conception $\mathrm{C}$, but not conception D, also demonstrated conceptions $\mathrm{A}$ and $\mathrm{B}$, thus reinforcing the inclusivity and expanding awareness of the categories. The reverse did not apply, however.

Two teachers, ILMT 5 and ILMT 8 whose survey responses evinced conceptions A and B showed no evidence of the other two conceptions, and one teacher who held conception A demonstrated none of the other three conceptions, further reinforcing one-way inclusivity of increasing complexity from Category A through Category D. The data from only one teacher-participant (ILMT 10) seems to violate this inclusivity. Another interesting finding, as shown in Table 1, is that only ILMTs 1-4, who participated in the online survey, demonstrated Category D conceptions, the most complex understanding of professional learning in mathematics.

Table 1.Distribution of Conceptions of Professional Learning by ILMTs

\begin{tabular}{|c|c|c|c|c|}
\hline $\begin{array}{c}\text { Participan } \\
\text { t/Catego } \\
\text { ry }\end{array}$ & A. & B. & C. & D. \\
\hline ILMT 1 & $\checkmark$ & $\checkmark$ & $\checkmark$ & $\checkmark$ \\
\hline ILMT 2 & $\checkmark$ & $\checkmark$ & $\checkmark$ & $\checkmark$ \\
\hline ILMT 3 & $\checkmark$ & $\checkmark$ & $\checkmark$ & $\checkmark$ \\
\hline ILMT 4 & $\checkmark$ & $\checkmark$ & $\checkmark$ & $\checkmark$ \\
\hline ILMT 5 & $\checkmark$ & $\checkmark$ & & \\
\hline ILMT 6 & $\checkmark$ & & & \\
\hline ILMT 7 & $\checkmark$ & $\checkmark$ & $\checkmark$ & \\
\hline ILMT 8 & $\checkmark$ & $\checkmark$ & & \\
\hline ILMT 9 & $\checkmark$ & $\checkmark$ & & \\
\hline ILMT 10 & $\checkmark$ & & $\checkmark$ & \\
\hline
\end{tabular}

\subsection{Visual Representation of the Outcome Space}

As Larsson and Holmstrom demonstrate in their phenomenographic study of anesthesiologists' 
conceptions of their work, "the analysis of the logical relations between the categories of description makes it possible to create a map" [19] (p. 58) of the different ways of experiencing a given phenomenon. The relationships between the four ways of experiencing professional learning in mathematics are shown in Figure 1. The figure generally is a map representing the collective experiences of professional learning in mathematics of the 10 ILMTs.

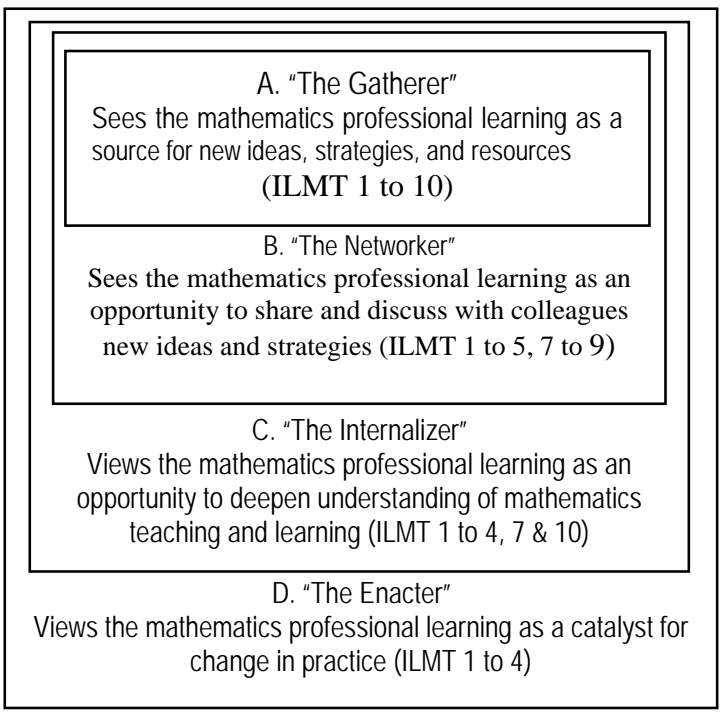

Figure 1. A category map of experiences of professional learning in mathematics

\section{Discussion}

The study was limited to a particular group of teachers involved in a particular series of professional learning opportunities focused on teaching mathematics through problem solving. According to Akerlind, "ideally, the outcomes [of a phenomenographic study] represent the full range of possible ways of experiencing the phenomenon in question” [13] (p. 323). However, "any outcome space is inevitably partial, with respect to the hypothetically complete range of ways of experiencing a phenomenon" [13] (p. 328) and "reflects both the data and the researchers' judgments in interpreting the data” [13] (p. 329).

The different conceptions of professional learning in mathematics are seen as representing "different breadths of awareness" [14] (p. 634). Thus, as the categories within the outcome space ascend, teachers have a broader awareness of the various aspects of, or ways of experiencing, professional learning in mathematics. For at least one teacher in the study, the way of viewing professional learning is seen only as a source for teaching resources (Category A). This teacher appears to see professional learning as opportunities to take ideas and materials from the professional learning session to the classroom. For three other teachers in the study, professional learning is seen as an opportunity to participate in a support network of colleagues with whom they can share ideas and strategies (Category B), as well as a source for teaching resources. Both of these ways of experiencing professional learning in mathematics share a focus on the tools and strategies used in the teaching of mathematics. That is, they include an emphasis on resources including teaching strategies, though Category B includes an additional emphasis on developing, sharing and discussing these resources and strategies with other teachers. Teachers conceiving of professional learning as a network of collegial support not only take ideas and resources away from sessions, but they also bring ideas and resources with them to the professional learning.

A third way of viewing the professional learning that emerged in the study focuses on deepening one's own understanding of the teaching and learning of mathematics and involves challenging one's current beliefs and practices (Category C). Two teachers in the study with this conception of professional learning in mathematics reflect on what they do in the classroom and why, placing a greater emphasis on the role of the teacher in improving student learning. Along with the ideas and resources, they bring to the professional learning sessions their questions and wonderings about student learning and about the impact of their own practice on student learning.

Finally, the fourth way of understanding professional learning in mathematics expands from the third and includes enacting one's learning in the classroom (Category D). Seeing professional learning in this way - as a catalyst for change emphasizes even more a focus on the potential impact of the teacher's actions on student learning. The four teachers in the study with this conception of professional learning in mathematics seem to experience a back and forth interaction between their teaching practices in the classroom and the ideas and resources they explore during professional learning.

One of the interesting findings in the study was that only the four teachers who participated in the online survey demonstrated the most comprehensive conception of professional learning, experiencing professional learning as a catalyst for change in classroom practice. In fact, only two of the other six teachers demonstrated the second most complex conception, which involves a focus on deepening one's knowledge about the teaching and learning of mathematics. We speculate the reason for this discrepancy between ILMTs who participated in both surveys and those who participated only in the onsite professional learning survey lies in the difference in the two surveys themselves. However, as Akerlind [14] argues, reduced variation in the 
sample does not invalidate the ways of understanding that emerge from the data, as these ways of understanding should still be present in the larger population, it simply means that there may be additional ways of understanding that are not represented in the data. (p. 244)

Having addressed the first research question on categories of conceptions of professional learning, we now turn our attention to the second sub question: In what ways do intermediate lead math teachers' conceptions of their ongoing, collaborative professional learning suggest how their experiences will be enacted in the classroom?

The two general emphases evident in the categories - one on teaching tools and strategies and the second on the impact of teachers' actions on student learning - appear to be related to what other researchers have found regarding conceptions of mathematics and conceptions of teaching $[6,14]$. It may be that teachers in the present study who demonstrated conceptions of professional learning in mathematics focused on teaching tools and strategies (Categories A and B) hold views of mathematics that align with the procedural-formalist paradigm presented by Ellis and Berry [6]. Indeed, since teachers with a procedural-formalist view see mathematics as a set of facts, skills, and procedures, we might infer that these teachers would be interested in gaining, through professional learning opportunities, tools and strategies that would provide an efficient means for students to learn these facts, skills, and procedures.

On the other hand, teachers who demonstrated conceptions of professional learning in mathematics as opportunities to deepen their understanding of mathematics teaching and learning (Category C) or as a catalyst for change in practice (Category D) may have conceptions of mathematics more aligned with a reform teaching that we defined earlier, where mathematics is seen as interconnected concepts that are understood through human interaction $[3,5,6]$. These teachers might be interested not only in strategies and tools for helping students understand and make connections among mathematical facts and procedures, but also in the ways in which their actions and interactions with students impact students' understanding.

It is also possible to imagine a parallel between different sets of assumptions about what mathematics is and how it might be acquired [3, 4, 5] and different sets of assumptions about what the purpose of professional development is and how that purpose should be realized. Teachers in the study who experienced professional learning as gatherers (Category A) or networkers (Category B) may see the purpose of professional learning as providing content, and strategies for developing and delivering that content. Therefore, they focus on the tools and strategies gained through professional learning.
Conversely, teachers in the study who experienced professional learning in mathematics as internalizers (Category C) or enacters (Category D) may be more likely to see the purpose of professional learning as similar to the purpose of mathematics underlying teaching through problem solving - that is, to interpret, organize, inquire about and construct meaning about one's lived world [4]. As a result, they may expect to have opportunities to question, challenge, practice new ideas and strategies, and reflect on their learning.

Also, teachers' conceptions about teaching in general - ranging from a teacher-focused conception, or knowledge transmission orientation, to a studentfocused conception, or learning facilitation orientation [13, 14, 15] - might be at play here. Looking at the present study findings, we may infer similar differences in conceptions about teaching from teachers' conceptions about professional learning. For example, phrases, classified as Category A or B in terms of ways of experiencing professional learning, a knowledge transmission orientation, or teacher-centered conception, of teaching was evident: ILMT 6 (Category A only) talked about "great ideas on how to deliver [italics added to emphasize orientation and center of conception] ILMT 5 (categories A \& B only) talked about "receiving ideas/plans that I can implement. Whereas ILMT 8 (categories A \& B only) mentioned "a chance for dialogue with other math teachers about what they're doing. In contrast, phrases from teachers, also classified in Category C or D for their conceptions of professional learning, demonstrate conceptions of teaching as student-centered or having a learning facilitation orientation: "[I] developed a better understanding of how students learn . . . to allow the students to struggle and to feel the joy of solving the problem on their own" (ILMT 3). "Teaching through problem solving ... allows them [students] to make connections to the real world” (ILMT 2). "[Students] were more concerned about showing their work and explaining it" (ILMT 3).

If a relationship exists between teachers' conceptions of professional learning and their conceptions of teaching, we might use that relationship to draw some conclusions about how teachers' professional learning is enacted in the classroom. As Akerlind found, teachers with a teacher-centered understanding of teaching focus their attention on what they, as the teacher, are doing, while teachers with a student-centered understanding of teaching focus their attention on what the students are experiencing [14]. Similarly, teachers with a view of professional learning as either a source for resources or an opportunity to share and discuss strategies with other teachers (Category A or B) are likely to focus on their own actions as they strive to implement the ideas and 
lessons they received during the professional learning opportunities. Alternately, teachers with a student-centered conception of teaching and professional learning - that is, those whose conceptions of professional learning included Category C or D - are likely to focus on how their actions impact student learning. The latter group may be more willing to try different approaches and to adapt their teaching to the learning needs of the students. Our data provided evidence of this type of student-centered enactment of teachers' professional learning: Math talk has helped a lot - encouraging kids to use proper terminology/language to explain their thinking more regularly and also question each other and defend their own ideas (ILMT 10).

As Akerlind argues, teachers with a studentcentered understanding of teaching take their "students' role in learning into account in designing and monitoring teaching-learning situations" [14] (p. 634).

Elsewhere, we use findings from this study to relate teacher's levels of efficacy for teaching mathematics through problem solving to their conceptions of professional learning and consequently to their instructional practice.

\section{Conclusions}

This study raises questions about the other conceptualizations that might exist among both inservice and preservice teachers. It also calls for reflecting on whether more complex conceptions of professional learning such as Category C and D are desirable for all teachers including non specialists and those that do not identify themselves as leaders at teaching mathematics. More important is the implication that mathematics professional development facilitators do not only need to encourage the development of more sophisticated conceptions of mathematics, its teaching and learning but also the development of more sophisticated conceptions of professional learning in mathematics teaching. All these conceptions are closely related.

Further, research on teacher professional development programs also ought to focus on studying how teachers develop more sophisticated conceptions so as to be able to design environments that foster these conceptions. There is also need to studying profiles of teachers with more sophisticated conceptions to see how these are developed and sustained and how they relate to classroom practice.

Finally, activities on patterns of variation could be used to elicit expansion in teachers' conceptions of both student learning and professional learning in mathematics. These activities would be an added characteristic of effective professional development.

\section{Acknowledgements}

We wish to acknowledge Dr. D. Kotsopoulos the supervisory committee member of the thesis whose research is reported in this paper

You must include your fully-completed, signed copyright release form when you submit your final paper. We must have this form before your paper can be published in the journal. The copyright form is available as a Word file.

\section{References}

[1] A. H. Schoenfeld, "Problem Solving in the United States, 1970-2008: Research and theory, practice and politics”. ZDM Mathematics Education, 39, (2007): pp. 537-551.

[2] M. Santos-Trigo, "Mathematical problem solving: an evolving research and practice domain". ZDM Mathematics Education, 39 (2007): pp. 523536.

[3] A. H. Schoenfeld, "When good teaching leads to bad results": The disasters of "well-taught" mathematics classes. Educational Psychologist, 23, no. 2 (1998), pp. 145-166.

[4] Fosnot, C. and Dolk, M., Young mathematicians at work: Constructing fractions, decimals, and percents. Portsmouth, NH: Heinemann, (2002).

[5] Sfard, A. 'Participationist discourse on mathematics learning’. In J. Maasz, \& W. Schloeglmann (Eds.), New mathematics education research and practice, Rotterdam: Sense Publishers. (2006), pp. 153-170.

[6] M. Ellis, and R. Berry, “The paradigm shift in mathematics education: Explanations and implications of reforming conceptions of teaching and learning”. The Mathematics Educator, 15, no. 1, (2005), pp. 7-17.

[7] Hiebert, J. and Wearne, D. 'Developing understanding through problem solving'. In $\mathrm{H}$. Schoen (Ed.), Teaching mathematics through problem solving, Grades 6-12, Reston, VA: NCTM. (2003), p. 3-13.

[8] Stein, M., Boaler, J., and Silver, E. 'Teaching mathematics through problem solving: Research perspectives'. In H. Schoen (Ed.), Teaching mathematics through problem solving, Grades 6-12, Reston, VA: NCTM. (2003), p. 245-256.

[9] B. Davis, and D. Simmt, "Mathematics-forteaching: An ongoing investigation of the mathematics that teachers (need to) know". 
Educational Studies in Mathematics, 61, no. 3, (2006), pp. 293-319.

[10] K. Koellner, and "others" "The problem-solving cycle: A model to support the development of teachers' professional knowledge”. Mathematical Thinking and Learning, 9, no. 3, (2007), pp. 273303.

[11] G. Gadanidis, and I. Namukasa, "Mathematicsfor-teachers (and students)". Journal of Teaching and Learning, 5, no.1, (2007), pp. 13-22.

[12] T. Guskey, "Professional development and teacher change". Teachers and Teaching: theory and practice, 8, no 3/4, (2002),pp. 381-391.

[13] G. Akerlind, “A new dimension to understanding university teaching". Teaching in Higher Education, 9, no. 3, (2004), pp. 363-375.

[14] G. Akerlind, "A phenomenographic approach to developing academics' understanding of the nature of teaching and learning". Teaching in Higher Education, 13, no. 6, (2008b), pp. 633-644.

[15] K. Wood, "The experience of learning to teach: changing student teachers' ways of understanding teaching”. Journal of Curriculum Studies, 32, no. 1, (2000), pp. 75-93.

[16] F. Marton, and M. Pang, "On some necessary conditions of learning". The Journal of Learning Sciences, 15, no. 2, (2006), pp. 193-220.

[17] Marton, F. and Tsui, A. Classroom discourse and the space of learning. Mahwah, NJ: Lawrence Erlbaum Associates, (2004).

[18] F. Marton, "Phenomenography - Describing conceptions of the world around us". Instructional Science, 10, no. 2, (1981),pp. 177-200.

[19] J. Larsson, and I. Holmstrom, "Phenomenographic or phenomenological analysis: does it matter? Examples from a study on anesthesiologists' work". International Journal of Qualitative Studies on Health and Well-being, 2, no. 1, (2007), pp. 55-64.

[20] L. Svensson, "Theoretical foundations of phenomenography”. Higher Education Research \& Development, 16, no. 2, (1997), pp. 159-171. 